\title{
Sex Workers Outreach Project Inc.: Multicultural Project
}

Na Mon Cheung*

Sex Workers Outreach Project (SWOP), Australia

\begin{abstract}
A lack of understanding of migrant sex work, and of migrant sex workers, leads to legal and cultural barriers being unintentionally placed between migrant sex workers and health and information services. These legal and cultural barriers compromise the ability of migrant sex workers to access services and to control their own sexual health, thus increasing risks of STI and HIV transmission. The incorrect conflation of migrant sex work with people trafficking and sexual slavery and the amplification of this incorrect conflation by popular media to levels of "moral panic" reinforce the barriers that migrant sex workers face to achieving good sexual health.
\end{abstract}

Keywords: HIV/AIDS; Sex workers; Condoms

\section{Introduction}

My work for SWOP is not only to distribute condoms!

Prior to my role as a Chinese Outreach Officer at SWOP NSW, I have work in different occupations like receptionist, waitress and makeup artist...just like others.

Sex work is not my only occupation. I choose to travel for sex work and have done sex work in many countries. I believe that sex work is work.

There is no special reason to do sex work, just when you need to work or make a living to survive and to pay your own bills. I only wanted to build a better life for myself. An Asian woman who has an education, has a career, is financially stable, and provides her basic needs, has a home and a family, is an independent woman.

Governments and media use the conflation of "sex slavery" or "victim of trafficking" with sex work to create a moral panic and governments make efforts to address perceived issues of labor exploitation of migrant sex workers by making legal pathways to sex work and for migration difficult. Furthermore, this well publicized conflation creates stigma and barriers for migrant sex workers to access HIV/AIDS prevention, medical services and support [1].

As a migrant sex worker, I and other migrant sex workers, find a need of having someone who can speak our languages and understand our cultural sensitives to be available to support us to go through difficult times and to break the barriers that exist to access to services in a non-judgmental manner.

My life experience and the life experience of my peers informs me of the importance of being a positive role model migrant sex workers, as a peer educator and to also represent migrant sex workers' community voice to lobby and advocate for migrant sex workers' human rights in order to improve our health outcomes.

\section{Background}

The Sex Workers Outreach Project (SWOP) is Australia's longest established community based peer education sex worker organization and is focused on HIV, STI and Hepatitis C prevention and health promotion for sex workers. Many of SWOP's service users are from migrant backgrounds and from culturally and linguistically diverse communities. The SWOP Multicultural Project is staffed by Chinese, Thai and Korean-speaking sex workers who provide non-judgmental and culturally specific information, and peer-to-peer support.

\section{SWOP's Multicultural Project Does}

- Peer support and health promotion.

- Distribution of safer sex supplies and safer injecting equipment on outreach or when sex workers drop in at our office.

- Visit migrant workers' workplaces including ones in urban, regional and rural areas.

- Peer support counselling and referral to free legal services for culturally and linguistically diverse sex workers.

\section{Materials and Methods}

Health education and support for migrant sex workers is targeted to and specific to migrant sex workers' workplaces, cultures and languages. The involvement of migrant sex workers themselves in conjunction with peer educators (who are also migrant sex workers) in project planning and implementation, and is essential to effective education and support of migrant workers.

Peer translated resources, peer interpreting support, workplace outreach, and sex industry specific health and safety training workshops provided in sex workers' first languages and in workplace specific language are essential tools in peer education, as are enabling social and legal environments.

\section{Empowerment}

- Through knowledge and rights we encourage workers to make positive decisions on their own work and health issues.

- We share our peer experiences and help migrant workers recognize that they are not alone.

\section{Resourceful}

We create resources by and for Chinese, Korean and Thai speaking sex workers.

*Corresponding author: $\mathrm{Na}$ Mon Cheung, Sex Workers Outreach Project (SWOP), Level 4, 414 Elizabeth street Sydney, Australia; Tel: +61292062166; E-mail: namonc@swop.org.au

Received December 13, 2016; Accepted January 16, 2017; Published January 23, 2017

Citation: Cheung NM (2017) Sex Workers Outreach Project Inc.: Multicultura Project. J AIDS Clin Res 8: 656. doi: 10.4172/2155-6113.1000656

Copyright: (c) 2017 Cheung NM. This is an open-access article distributed unde the terms of the Creative Commons Attribution License, which permits unrestricted use, distribution, and reproduction in any medium, provided the original author and source are credited. 
- We provide information on rights, laws and legislation.

- We provide HIV, Hepatitis C, STIs and sexual health information.

- We provide Health and workplace safety information

\section{Education and capacity building}

Workshops created and held by peers for our peers:

- Campaigns for migrant sex workers to raise awareness and knowledge of HIV and sexual health.

- Workplace health and safety, skills share and training.

\section{Advocacy}

- Advocate for migrant sex workers rights

- Decriminalization of sex work, and work with workplace management to support them to provide safer workplace environment for migrant sex workers.

- Build rapport with service providers to support migrant sex workers break down the barriers to obtain or access to HIV/ STI services.

\section{Representation}

- Culturally and linguistically diverse steering committee members involved in our resources project ensure our work represents our communities' voices.

- Training to services providers to help them provide better services for migrant sex workers.

- Attend public events and forums to increase general public's understanding of sex work break down the myths surrounding migrant sex workers.

\section{Networking}

- Domestically working with culturally and linguistically diverse peer educators and organizations from all states in Australia such as Scarlet Alliance, Australian Sex Workers Association, Sex Industry Network, Respect and Magenta [2].

- Internationally working with peer based organizations in Asia such as Empower, Sister and Swing in Thailand, Midnight Blue and the JJJ Association from Hong Kong to provide better services and support for sex workers who plan to sex work in NSW $[3,4]$.

\section{Results and Discussion}

In 2015-2016 we provided 5,106 occasional of services to sex industry workers in NSW Australia:

- 2,483 occasional of services were to non-culturally and linguistically diverse workers.

- 973 occasional of services were to Chinese sex industry workers (19.06\%).
- 719 occasional of services were to Thai SIW (14.08\%).

- 91 occasional of services were to Korean SIW (1.78\%).

We printed 17,976 resources, of which 6,083 (33.84\%) were in a language other than English or were in multiple languages.

We ran 9 workshops for culturally and linguistically diverse sex workers, including World AIDS Day, HIV Testing Awareness Week, Hepatitits B Awareness and the Jade Flower sex work skills share and workplace health and safety workshop.

\section{Conclusion and Recommendations}

The legal and cultural barriers that migrant sex workers experience are often stronger and higher than simple barriers of language. Identifying and overcoming the barriers faced by migrant sex workers cannot be achieved without input from the migrant sex worker communities. The provision of enabling environments, especially the decriminalization of sex work and the decriminalization of migrating sex workers, is essential to achieving long-term migrant sex worker health and HIV prevention $[5,6]$.

\section{Acknowledgement}

Cameron Cox, Chief Executive Officer SWOP Inc

\section{Conference}

This was a poster presentation by Na Mon Cheung from SWOP Inc. at the $21^{\text {st }}$ International AIDS Conference, Durban, South Africa (AIDS 2016).

\section{References}

1. Bates J, Berg R (2014) Sex workers as safe sex advocates: Sex workers protect both themselves and the wider community from HIV. AIDS Educ Prev 26: 191-201.

2. Jeffreys E (2014) Scarlet alliance brings sex worker migration to Canberra Australian Feminist Law Journal 28: 195-205.

3. Migrant and Multicultural Sex Worker Report 2012 (2012) Inner South Community Health Service.

4. Jeffreys E, Perkins R (2011) Sex work, migration, HIV and trafficking: Chinese and other migrant sex workers in Australia. Intersections: Gender and Sexuality in Asia and the Pacific 26: 8.

5. Renshaw L, Kim J, Fawkes J, Jeffreys E (2015) Migrant sex workers in Australia. AIC Reports 131.

6. Jeffeys E (2015) Migrant sex workers research in Australia. 4th Australian National Symposium on Sex Work. 